\title{
Comparison of the Results of Glassbone and Tricalcium Phosphate Graft Used in Bone Tumors
}

\section{Kemik Tümörlerinde Kullanılan Cam Greft ve Trikalsiyum Fosfat Greft Sonuçlarının Karşılaştırması}

\author{
Mahmut Nedim Aytekin'1, Fahri Emre 2 , Recep Öztürk ${ }^{3}$ \\ ${ }^{1}$ Ankara Yıldırım Beyazıt Üniversitesi Tıp Fakültesi, Ortopedi Ve Travmatoloji, Ankara \\ ${ }^{2}$ Gülhane Eğitim Ve Araştırma Hastanesi, Ortopedi Ve Travmatoloji, Ankara \\ ${ }^{3}$ Dr Abdurrahman Yurtaslan Ankara Onkoloji Eğitim Ve Araştırma Hastanesi, Ortopedi Ve Travmatoloji, \\ Ankara
}

Dergiye Ulaşma Tarihi:22.03.2020 Dergiye Kabul Tarihi:05.04.2020 Doi: 10.5505/aot.2020.83723

\section{ÖZET}

GİRİŞ ve AMAÇ: Tümörlerin neden olduğu kemik defektleri bazen kemiğin kendi dokusu ile iyileşmeyebilir. Bu gibi durumlarda, iyileşmeyi kolaylaştırmak veya başlatmak için kemik defektlerininn kemik grefti materyalleriyle doldurulması gerekebilir. Bu çalı̧̧madaki amacımız iyi huylu kemik kistlerinde kullanan cam greft (CG)(GlassBone NORAKER) ve trikalsiyum fosfat greft (TKF) sonuçlarını klinik ve radyolojik olarak karşılaştırmaktır.

YÖNTEM ve GEREÇLER: 2013 -2015 yılları arasında iyi huylu kemik tümörleri (çoğu basit kemik kisti (BKK) ve anevrizmal kemik kisti (AKK)) nedeniyle küretaj, koterizasyon ve grefonaj yapılan 41 hastaya greft olarak CG ve TKF greft kullanıldı. Hastalar CG ve TKF greft ile tedavi edilenler olarak 2 gruba ayrildı. Greft konsoludasyonu aylık çekilen röntgenlerle radyolojik olarak değerlendirildi. Hastaların klinik sonuçları retrospektif olarak değerlendirildi. BULGULAR: Ortalama yaş 22,0 (14-32 yaş arası) olan 20 erkek ve 21 kadın $(\% 51,2)$ mevcuttu. CG kullanılan hastalarda TKF kullanılan hastalara göre, 14.-16. Aylar arasında radyolojik olarak konsolidasyonun daha hızlı olduğunu gözlendi $(\mathrm{p}=0.0001)$. TARTIŞMA ve SONUÇ: İyi huylu kemik tümörlerinin tedavisinde, cam greftlerin trikalsiyum fosfat greftlerine alternatif olarak kullanılabileceği sonucuna vardık. Ayrıca cam greftlerle tedavi edilen hastaların radyolojik olarak daha hızlı füzyon gösterdiğini fark ettik.

Anahtar Kelimeler: Cam Greft, trikalsiyum fosfat, kemik tümörü,

INTRODUCTION: Bone defects caused tumors sometimes may not heal with bone tissue. In such cases, bone defects may need to be filled with bone graft materials to facilitate or start healing. The purpose of our study is to compare results of glass graft(GG) (GlassBone NORAKER) and tricalcium phosphate (TCP) grafts that we use in benign bone cysts clinically and radiologically.

METHODS: 41 patients with benign bone tumors (mostly simple bone cysts (SBC) and aneurysmal bone cysts (ABC) ) had been treated between either glass graft or tricalcium phosphate graft between 2013-2015. Patients were divided into two groups as those treated with GG and TCP grafts. Graft consolidation evaluated radiologically with x-rays monthly. RESULTS: There were 20 men and 21 women $(51.2 \%)$ with a mean age of 22.0 years (range 14-32 years). In patients using GG, compared to patients using TCP, radiological consolidation was observed faster between 14.-16. months $(p=0.0001)$. DISCUSSION AND CONCLUSION: We conclude that in the treatment of benign bone tumors glassbone can be used as an alternative to tricalcium phosphate grafts. We also noticed that patients treated with glassbone showed a faster rate of fusion radiologically.

Keywords: bioactive glass, tricalcium phosphate, bone tumor

\section{GíRiș}

Travma veya patolojik olayların neden olduğu kemik defektleri majör klinik ve sosyoekonomik problemlerdir.[1] Kemik greftleri ortopedik cerrahide kemik rejenerasyonunda kullanilan cerrahi prosedürlerdendir.[2] Dünyada her y1l 2 milyondan fazla kemik greftleme işlemi gerçekleştirilmektedir; ki bu kan transfüzyonundan sonra en sik doku transplantasyon işlemidir.[3]
Son 40 y1l boyunca rejeneratif tip araştırmacıları kemik özelliklerine benzeyen ve rezorbe olmayan malzeme üretmeye odaklanmıştır.[4]

Otolog kemik greftleri kemik defektleri için altın standart olarak kullanılmaktadır. Yüksek osteojenik kapasitede olmas1,immünolojik reaksiyonlara neden olmamas1, HIV ve HBV gibi virüs enfeksiyon taşımaya neden olmamasından dolayı tercih nedenidir. Ancak otogreftleringreft yetersizliğ $i$ ve morbidite (kronik ağr1,yara yeri problemleri, kan kayb1, vb.) gibi komplikasyonları 
mevcuttur . Allogreftlerde de bulaşıc1 hastaliklar ve immünolojik red gibi komplikasyonlar mevcuttur.[5-7] Allogreft ve otogreftteki bu komplikasyonlar greft olarak biyomateryalleri ön plana çıkarmaktadır.

Piyasada pek çok farklı kemik grefti mevcuttur ve ortopedistler, seramikler, biyoaktif camlar, demineralize kemik matriksi,allogreft ve kemik morfogenetik proteinleri de dahil olmak üzere çeşitli greftler arasından seçim yapabilir.

Biyoseramikler son 40 yıldır klasik kemik grefti olarak kullanılmaktadır.[8] CG (Cam Greft) 'ler ve TKF (Trikalsiyum Fosfat) greftleri biyomühendislikte yaygın olarak kullanılan seramik bazlı greftlerdir. Ayrıca CG'ler osteokondüktif ve antibakterial özelliğe sahip greftlerdir. $[9,10]$

$\mathrm{Biz}$ bu çalışmada sık görülen benignkemik tümörü tedavisinde kullanılan CG ve TKF greftlerin klinik ve radyolojik sonuçlarını retrospektif analiz etmeyi amaçladık.

\section{MATERYAL VE METOT}

Bu çalışmada Ocak 2013 ve Aralık 2015 yılları arasinda CG veya TKF greftile tedavi edilen ve histopatolojik incelemede BKK, AKK ya da diğer iyi huylu kemik tümörü tanısı konulan hastalar retrospektif olarak analiz edildi.Çalışmada Helsinki Deklerasyonu Prensipleri'neriayetedildi .Toplam bulunan 47 hastanın 41'i çalışmaya dahil edildi, 6 hastabir yıldan az takip süresi nedeniyle çalışma dışı bırakıldı. Tüm hastaların öyküsü, klinik muayene bulguları ve direk grafi ve MRI gibi radyolojik tetkikleri incelendi. Hastaların 21'i kadın 20'si erkekti. Hastalar küretaj ve koterizasyon sonrasi CG veya TKF greft ile greftlenen hastalar olarak 2 gruba ayrild. Toplam 22 hastada $(\% 53,6) \mathrm{CG}, 19$ hastada TKF kullanıldı (tablo 1). Tümörün boyutu $\mathrm{X}$ ray veya MRI ile ölçüldü. Hastalar Ankara Atatürk Eğitim ve Araştırma Hastanesi'nde ameliyat edildi. Ameliyat öncesi klinik ve radyolojik olarak iyi huylu olduğuna emin olunan bu hastalarda tanıyı doğrulamak için ameliyatta alınan küretaj materyalleri histopatolojik incelemeye gönderildi. Histopatolojik olarak anevrizmalkemil kisti (AKK) (12 hasta), basit kemik kisti(BKK) (10 hasta ) ve diğer iyi huylu kemik tümörü (19 hasta) olarak sınıflandırıldı. Ameliyatta korteksten dril ve osteotom yardımı ile oval bir kapak kaldırıldı. Tümör küret yardımı ile dikkatlice çıkarıldıktan sonra kavite duvarınaküretaj, burr ve koter uyguland1.KaviteCG yada TKF greft ile dolduruldu. Doldurulan kavite tümöre ulaşmak için açılan korteks parçası ile kapatıldı. Hastanede kalma süresi ortalama 1.5 gündü (1 gün- 3 gün aras1). Histopatolojik inceleme ve lokasyonla sinıflandırılan tümör tipleri tablo 1 de gösterilmiştir. Hastalar taburculuk sonrası 15. günde dikişlerini aldırmak için ve sonrasında aylık kontroller için polikliniğe çağrilıp klinik ve radyolojik olarak değerlendirildi.

\section{İstatistiksel Analizler}

Çalışmada yer alan sürekli sayısal değişkenlerin normal dağılıma uygunluğu ShapiroWilks testi ile incelendi. Sayısal değişkenlerin gösterimi için ortanca (çeyreklikler arası genişlik), ortalama \pm standart sapma ve minimum; maksimum tanımlayıcı istatistikleri kullanıldı. Kategorik değişkenlerin gösteriminde sayı (n) ve yüzde (\%) verildi.

Çalışma gruplarında kategorik değişkenlerin farklılı̆̆ının incelenmesinde Fisherexact test, Yates ki kare testlerinden, sayısal değişken değerlerinin karşılaştırılmasında ise Mann Whitney U testinden yararlanıldi.

Sayısal değişkenler arasındaki ilişki Spearmanrhokorelasyon katsayisı ile incelendi. Anlamlı ilişki belirlenmesi durumunda, korelasyon katsayısı $0.00-0.19$ aralığında ise "ilişki yok ya da önemsenmeyecek düzeyde düşük ilişki", $0.20-0.39$ aralığında ise "zayıf (düşük) ilişki", 0.40 - 0.69 aralığında ise "orta düzeyde ilişki”, $0.70-0.89$ aralığında ise "kuvvetli (yüksek) ilişki" ve 0.90 - 1.0 aralığında ise "çok kuvvetli ilişki" şeklinde yorumlandi.

İstatistiksel analizler ve grafikler için IBM SPSS Statistics 21.0 (IBM Corp. Released 2012. IBM SPSS Statisticsfor Windows, Version 21.0. Armonk, NY: IBM Corp.) ve MSExcel 2007 programları kullanıldı. İstatistiksel anlamlılık düzeyi $\mathrm{p}<0.05$ olarak kabul edildi.

\section{BULGULAR}

$\mathrm{Bu}$ çalışmada ortalama yaşı 22,0 (14-32 yaş arasi) olan, 20 erkek ve 21 kadın $(\% 51,2)$ 
toplam 41 hasta mevcuttu. Hastaların ortalama takip süresi 44 ay (12- 86 ay arası) idi.

$X$ ray ve MRI ile ölçülen tümör hacmi CG kullanilanlarda ortalama $20.7 \mathrm{~cm} 3$ (SD 17.7),TKF greft kullanılanlarda ortalama 19.5 cm3 (SD 20.2) idi.

3 hasta büyüyen rezidüel kistler 1 hasta da enfeksiyon nedeni ile 2.kez ameliyat edildi. Bu hastaların 2 si CG, 2 si TKF greft ile tedavi edilmişti. Enfekte olan hastada TKF greft kullanılmıştı. İkinci ameliyatlarında da yine aynı greftler kullanıldı.

Kaynama klinik olarak ağrının geçmesi ve radyolojik olarak X Ray ile değerlendirildi. 3. ayda yeniden ameliyat edilen hastalar dahil bütün hastalarda radyolojik kaynama görüldü.

CG kullanılan hastalarda TKF kullanilan hastalara göre, 14.-16. Aylar arasinda radyolojik olarak konsolidasyonun daha hızlı olduğunu gözlendi $(\mathrm{p}=0.0001)$.

16. Ay sonunda CG kullanilan hastaların X Ray'ındaameliyat öncesi ile karşılaştırıldığında istatistliksel olarak anlamlı olacak şekilde kavite görülmedi.(p:0.0003) TKF greft kullanılan hastalarda ise ameliyat öncesi görüntülerle karşılaştırıldığında 14 . Ayda kavite hacmi azalmaya başladı ve 20 . Ayda anlamlı bir farklılık gösterildi.(p:0.01) buraya kadar CG ve TKF greft kullanılan hastalar arasinda anlamlı bir farklilık vardi.(p:0.01) Ancak 36. Ay dan sonra bu iki grup arasında bir farklılık görülmedi.(p:0.78)

Tablo 1. Hastaların Demografik Verileri

\begin{tabular}{ll}
\hline $\begin{array}{l}\text { Veriler } \\
\text { Cinsiyet, n(\%) } \\
\text { Erkek }\end{array}$ & $\begin{array}{l}\text { Toplam } \\
\text { N=41 }\end{array}$ \\
$\begin{array}{l}\text { Kadın } \\
\text { Yaş, yıl }\end{array}$ & $20(48,8)$ \\
Ortalama & $21(51,2)$ \\
Ortanca (min-maks) & \\
& 22,0 \\
Yön, n(\%) & $24(14,0-$ \\
Sol & $32,0)$ \\
Sağ & \\
Kullanılan greft n(\%) & $22((53,6))$ \\
Cam Greft, BKK & $19(46,4)$ \\
TKF Greft, BKK & \\
Cam Greft, AKK & $6(14,6)$ \\
& $4(9,7)$ \\
TKF Greft, AKK & $6(14,6)$ \\
TKF İyi Huylu Kemik Tümörü & $9(21,9)$ \\
Cam Greft İyi Huylu Kemik & $10(24,3)$ \\
Tümörü & \\
Takip Süresi, aylar & \\
\hline
\end{tabular}

$\begin{array}{ll}\text { Ortalama } & 54,0 \\ \text { Ortanca (min-maks) } & 57(12,0- \\ & 126,0)\end{array}$

BKK:Basit kemik kisti, AKK:Anevrizmal kemik kisti TKF:Trikalsiyon fosfat
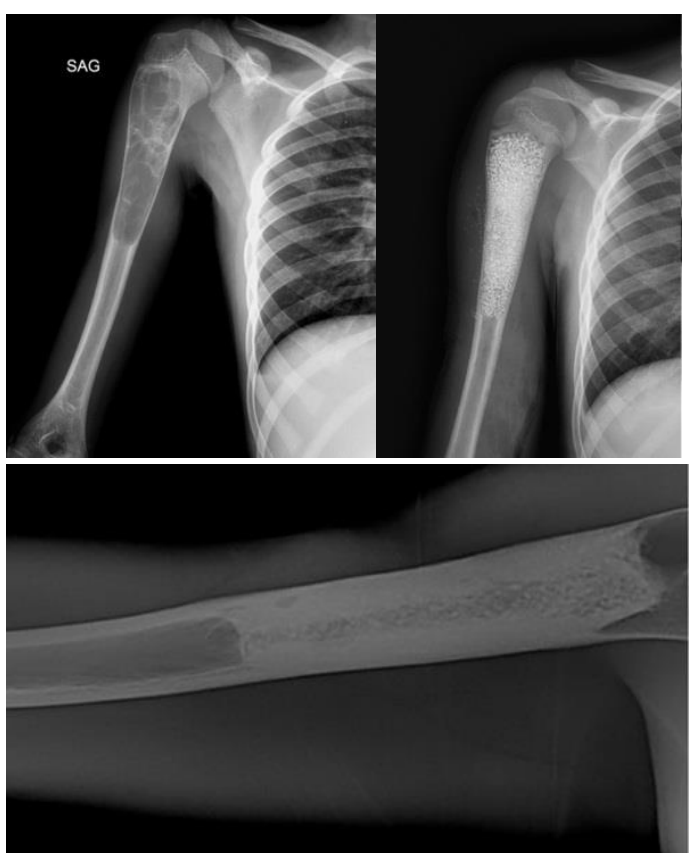

Resim 1: 14 yaşında erkek hastada sağ humerus proksimalyerleşimli AKK a) humerus proksimalinden diafize uzanan lobüle kontürlü septalı kistik lezyon direk grafisi b) küretaj + allogreftleme (cam greft) sonrası post-operatif direk grafisi c) post-operatif 10. ay grafisi; greft füzyonu görülmekte

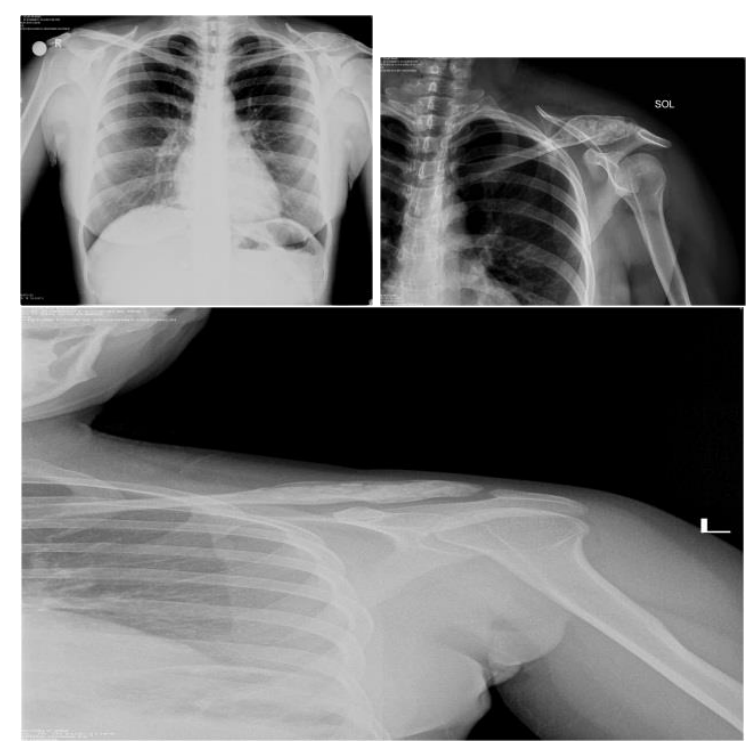

Resim 2: 40 yaşında kadın hastada sol klavikula yerleşimli AKK. A) direk grafide distal 
klavikulada diafize uzanan septalı kistik lezyon direk grafisi b) küretaj + allogreftleme (trikalsiyum fosfat) sonrasi post-operatif direk grafisi c) post-operatif 4. ay grafisi

\section{TARTIŞMA}

Ülkemiz verileri incelendiğinde basit kemik kisti osteokondrom ve enkondromdan sonra en s1k görülen 3. benign kemik tümörüdür(\%14) ve anevrizmal kemik kisti (\%9) s1k görülen benign kemik tümörlerinden biridir(11).

İyi huylu kemik tümörleri genellikle defektin kürete edilmesi ve oluşan defektin doldurulması ile tedavi edilir. Defektler için günümüzde kemik çimentosu, sentetik kemik grefti, allogreft kemik ve otogreft kemik kullanılmaktadır. Kemik çimentosu, kemik stoğunu korumamaktadır. Ayrıca sertleşmiş çimento, kemikle aynı biyomekanik özelliklere sahip değildir (12). Allogreftlerin bulaşıc1 hastalık, derin enfeksiyon venonunion riskleri mevcuttur.[13] Otolog kemik greftleri kemik defektleri için altın standart olarak kullanılmaktadır. Yüksek osteojenik kapasitede olmas1, immünolojik reaksiyonlara neden olmamas1, HIV ve HBV gibi virüs enfeksiyon taşımaya neden olmamasından dolayı tercih nedenidir. Ancak otogreftleringreft yetersizliği ve morbidite ( kronik ağrı,yara yeri problemleri, kan kaybı gibi) gibi komplikasyonlar1 mevcuttur. $\mathrm{Bu}$ komplikasyonlardan dolay1 sentetik greftlereyönelinmiştir.

Sentetik greftlerin kullanımı ile bulaşıcı hastalık riski ortadan kalkar, ayrıca sentetik greftlerin kullanımı, donör saha morbiditesine neden olmamaktadır. Diğer avantajları ise sinırsiz miktarda elde edilebilmeleri ve erken fonksiyonel rehabilitasyona izin verebilecek yeterli mekanik destek sağlayabilmeleridir. Sentetik greftlerin biyouyumlu olduğu ve büyük boyuttaki kemik defektlerinin rekonsriksiyonu amaçlı kullanıldığ da bilinmektedir.[14] İdeal kemik greftinden, otolog kemik greftinde olduğu gibi osteokondüktif ve osteoindüktüf özellik göstermesi beklenilir. Aynı zamanda sentetik greftler, viral veya bakteriyel kontaminasyon riski olmadan kolayca temin edilebilirler. Bu greftler uygulaması kolay, uygun maliyetli olmalıdırlar ve immünojenik olmamalıdırlar.[15] CG ler osteokondüktif özelliklerinin yanında TKF greftten daha fazla osteostimülatif özelliğe sahiptirler.[16] CG ler ayrica anjiogenezi aktive eden ve antibakterial özelliğe sahiptirler.[17]

$\mathrm{Bu}$ çalışmadaki amacımız iyi huylu kemik tümörleri defektinde TKFgreft ve CG kullandığımız hastaların greftin kemiğe konsolüdasyon süresini radyolojik olarak karşılaştırmaktı.

Ewaniev ve arkadaşları 2007-2012 y1lları arasında opere ettikleri 24 benign kemik tümörü olan hastayı retrospektif olarak incelediler. İntralezyonel küretaj sonrası oluşan kemik defektleri, "Pro-Dense (Calcium Sulfate-Calcium Phosphate Synthetic Bone Graft Composite)" ile rekonstrukte ettiler. Prodense ile tam radyolojik rezorbsiyonun ve yeni kemik oluşumunun tipik olarak ameliyat sonrası 5. ayda görüldüğünü saptadılar(18).

Saikia ve ark. TKF greftveya HA (hidroksiapetit) ile rekonstrukte edilen 24 hastayı incelemişler. 24 hastanın 20'sinde HA, 4'ünde beta TCP kullanılmış, kaynama süresi ortalama 9 ay (6- 18 ay) olarak saptamışlar (19).

Linfors ve ark. İyi huylu kemik tümörlerinde CG ve otogreft kullandıkları 25 hastanın sonuçlarını karşılaştırmışlar. CG kullandıları hastalarda kaynama 12 ay da başladığını ve 24 ayda preoperatif duruma göre anlamlı farklılık olduğunu görmüşler. Otogreft kullanilan hastalarda ise 12 ayda konsolüdasyonun olduğunu ve kemikboşluğnun olmadığ1 görülmüşs.[20]

Ülkemiz çalışmaları incelendiğinde, Çelebi ve ark. Kansellöz greft ve sentetik grefti karşılaştırdıkları çalışmalarında, sentetik greftte ortalama 149 gün, kansellözgreftte 103 gün kaynama süresi elde ettiler. $\mathrm{Ve}$ bu fark istatistiksel olarak anlamlıydı[7]. Ülkemizde birçok çalışmada greft kullanımı sonuçları bildirilmektedir [21].

Bizim yaptığımız çalışmada greftin konsolüdasyon süresi 36. Aya kadar CG kullanılan hastalarda istatistliksel olarak daha hızlıydı. Ancak 36. Aydan sonra klinik ve radyolojik bir fark olmadığını gördük. CG in anjiogenezi aktive ettiğinden dolayı greft konsoludasyonunun daha erken olduğunu düşünmekteyiz.

$\mathrm{Bu}$ çalışmanın bazı kısıtlılıkları mevcuttu. Çalışma retrospektif analizdi ve hasta sayıs1 nispeten azd1. Bununla beraber, bu greftlerin daha iyi anlaşılması için uzun süreli takiplerle ileriye dönük randomize çalışmalara ihtiyaç vardır. 


\section{SONUÇ}

Sonuç olarak iyi huylu kemik tümörü tedavisinde, cam greftlerintrikalsiyum fosfat greftlerine alternatif olarak kullanılabilir. Ayrica cam greftlerle tedavi edilen hastalarda radyolojik olarak daha hızlı füzyon görülür.

Yazarlar arasında hiçbir çıkar çatışması yoktur.

\section{REFERANSLAR}

1-Bottagisio M, Lovati AB, Lopa S, Moretti M. Osteogenic Differentiation of Human andOvine Bone MarrowStromal Cells in response to $\beta$ Glycerophosphate and Monosodium Phosphate. Cell Reprogram. 2015;17(4):235-42. doi: 10.1089/cell.2014.0105.

2-Dimitriou R, Jones E, Mc Gonagle D, Giannoudis PV. Bone regeneration: currentconceptsandfuturedirections. BMC Med. 2011;31;9:66. doi: 10.1186/1741-7015-9-66.

3-Campana V, Milano G, Pagano E, Barba M, Cicione C, Salonna G, Lattanzi W, Logroscino G. Bone substitutes in orthopaedicsurgery: frombasicsciencetoclinicalpractice.J Mater Sci Mater Med. 2014;25(10):2445-61. doi: 10.1007/s10856-014-5240-2.

4- Hench LL, Jones JR. BioactiveGlasses: FrontiersandChallenges. Front BioengBiotechnol. 2015;30(3):194. doi: 10.3389/fbioe.2015.00194.

5-Betz RR. Limitations of autograftandallograft: New syntheticsolutions. Orthopaedics. 2002;25(5 Suppl):561-570.

6-Giannoudis PV, Dinopoulos H, TsiridisE.Giannoudis, P. Bone substitutes: an update. Injury. 2005 Nov;36 Suppl 3:S20-7. Doi: 10.1016/j.injury.2005.07.029

7- Çelebi F, Kekeç AF, Öztürk R. A comparativestudy of artificial bone graftversusallograft in thereconstruction of defectsafterbenigntumorcurettage. ActaOncol Tur. 2018; 51(2): 151-58. Doi: 10.5505/aot.2018.26056

8- Laurencin, C. Bone graftsubstitutes; ASTM International: West Conshohocken, PA, 2003; p 260.

9-Hench LL. Bioceramics: Fromconcepttoclinics. J AmCeramSoc 1991;74:1487-510.

10-Virolainen P, Heikkila J, Yli-Urpo A, Vuorio E, Aro HT. Histomorphometricandmolecularbiologiccompa rison of bioactiveglassgranulesandautogenous bone grafts in augmentation of bone healing. J Biomed Mater Res 1997;35:9-17.

11- Öztürk R, Arıkan ŞM, Bulut EK,et al. Distribution andevaluation of bone andsofttissuetumorsoperated in a tertiarycarecenter. ActaOrthopTraumatolTurc
2019;53:189-94.

doi:

10.1016/j.aott.2019.03.008.

12-Campanacci M, Capanna R, Fabbri N, Bettelli G. Curettage of giant cell tumor of bone. Reconstruction with subchondral grafts and cement. ChirOrganiMov. 1990; 75(1 suppl):212-3.

13-Temple HT, Malinin TI. Microparticulatecorticalallograft: an alternativetoautograft in thetreatment of osseousdefects. Open Orthop J. 2008;2:91-6doi: 10.2174/1874325000802010091.

14-Huang Y, Jin X, Zhang X, Sun H, Tu J, Tang $\mathrm{T}$, Chang J, Dai K. Invitroand in vivoevaluation of akermanitebioceramicsfor bone regeneration. Biomaterials 2009;30:5041-8.Doi: 10.1016/j.biomaterials.2009.05.077

15-Hench LL. An introductiontobioceramics. ImperialCollegePress, 2003; London p.620.doi: $10.1142 / \mathrm{p} 884$

16-Oonishi H, Kushitani S, Yasukawa E, Iwaki H, Hench LL, Wilson J, Tsuji E, Sugihara T. Particulatebioglasscomparedwithhydroxyapatite as a bone graftsubstitute. ClinOrthopRelatRes1997; 334:316-25.

17-Hench LL. Bioceramics: Fromconcepttoclinics. J AmCeramSoc 1991;74:1487-510.

18-Evaniew N, Tan V, Parasu N, JurriaansE. Finlay K,Deheshi B, Ghert M. Use of a CalciumSulfate-CalciumPhosphateSynthetic

Bone GraftComposite in theSurgical Management of Primary Bone Tumors. Orthopaedics 2013;36(2):216-22. doi: 10.3928/01477447-20130122-25.

19-Saikia KC, Bhattacharya TD, Bhuyan SK, Talukdar DJ, Saikia SP, Jitesh P. Calciumphosphateceramics as bone graftsubstitutes in filling bone tumordefects. Indian J Orthop. 2008; 42(2):169-72.doi: 10.4103/0019-5413.39588.

20-Lindfors NC, Heikkilä JT, Koski I, Mattila K, Aho AJ. Bioactiveglassandautogenous bone as bone graftsubstitutes in benign bone tumors.Journal of

BiomedicalMaterialsResearchPart B: AppliedBiomaterials, 2008; 90B(1):1316. doi:10.1002/jbm.b.31263

21- Öztürk R, C Ulucaköy, İB Atalay, A Yapar, $\mathrm{Y}$ Karakoç. Management and retrospective analysis of pelvic ramus tumors and tumor-like lesions: Evaluation with 31 cases Jt Dis Relat Surg 31 